\title{
A presença ausente do racial: discursos políticos e pedagógicos sobre História, "Portugal" e (pós-)colonialismo ${ }^{1}$
}

\section{The absent presence of racial: political and pedagogical discourses on History, 'Portugal' and (post)colonialism}

\author{
Marta Araújo ${ }^{2}$ \\ Silvia Rodríguez Maeso ${ }^{3}$
}

\begin{abstract}
RESUMO
Este artigo analisa como, nos discursos políticos e no contexto educativo português, o racial se insere num jogo de in/visibilidades, sendo considerado como resultante da presença do "outro" da colónia e, logo, naturalmente irrelevante para a formação do espaço nacional-metropolitano e, de modo geral, para a formação da noção de "Europeidade". A partir desta análise, ilustramos a despolitização do racismo via a naturalização do colonialismo e a reificação do "imaginário imigrante"; neste sentido, o racismo é interpretado como algo que sucede aos outros - etnorracialmente marcados - mas que não diz respeito ao que "nós" somos, um "nós" que, aliás, nunca é questionado. O texto está dividido em três partes: (i) examinamos a consolidação da presente ausência do racial considerando como se tem constituído um ciclo de silêncios e consensos sobre o racial na própria ação de combate ao racismo - marcada pelo antirracialismo - de organizações globais como a UNESCO. Examinaremos ainda como a dissolução do racial está a ser produzida através da associação entre racismo e imigração no contexto europeu contemporâneo, tanto na política como na academia; (ii) analisar-se-á o trabalho empírico e os livros didáticos de história contemporâneos que

${ }^{1}$ A expressão "a presença ausente de raça" foi utilizada anteriormente por Michael Apple

${ }^{2}$ Doutorada em Sociologia da Educação pela Universidade de Londres e Investigadora do Centro de Estudos Sociais - Universidade de Coimbra, Portugal. E-mail: marta@ces.uc.pt

${ }^{3}$ Doutorada em Sociologia Política pela Universidade do País Basco e Investigadora do Centro de Estudos Sociais - Universidade de Coimbra, Portugal. E-mail: srodrig@ces.uc.pt
\end{abstract} (1999). 
realizámos em Portugal que mostram como, nos debates sobre a história e, mais concretamente, sobre o ensino do colonialismo e da escravatura, se tem esvaziado a sua relevância política e evadido o racial para compreender a chamada escravatura Atlântica dos séculos XV ao XIX; (iii) finalmente, concluímos com uma análise dos contornos daquilo a que denominamos o "consenso (pós-)colonial" em Portugal, inserido num contexto mais amplo de esvaziamento da plausibilidade de um vocabulário que dê conta do racial/ racismo nas sociedades contemporâneas.

Palavras-chave: "raça"/racismo; discursos públicos; História e seu ensino; Portugal (pós-)colonial.

\begin{abstract}
This article examines how in Portugal, in political discourse and in the educational context, 'race' is part of a game of in/visibility. The racial, being considered as a result from the presence of the "other" from the colony, is therefore naturally irrelevant to the formation of the national-metropolitan space and, more generally, to the notion of "Europeanness". From this analysis, we illustrate the depoliticization of racism through the naturalization of colonialism and the reification of the 'immigrant imaginary'; accordingly, racism is understood as something that happens to "others" - ethno-racially marked - but that does not relate to what "we" are, a "we" that, actually, is never questioned. This paper is divided in three sections: (i) we examine the consolidation of the absent presence of the 'racial' considering how a cycle of silence and consensus has been consolidated by the very initiatives to combat racism - marked by anti-racialism - by global organizations such as UNESCO. We further examine how the dissolution of the 'racial' is being produced by the association between racism and immigration in the contemporary European context, both in politics and in faculty; (ii) we present our empirical work and analysis of contemporary history textbooks in Portugal. We show that debates about history and, more specifically, about the teaching of colonialism and slavery have emptied its political relevance and evaded the 'racial' in the understanding of so-called Atlantic slavery, since the fifteenth to the nineteenth centuries, (iii) finally, we conclude with an analysis of the contours of what we call the "(post) colonial consensus" in Portugal, within a broader context of the emptying of the plausibility of a vocabulary that takes into account 'racial'/racism in contemporary societies.
\end{abstract}

Keywords: 'racial'/racism; public discourses; History and its teaching; (Post) colonial Portugal. 
E um esboço geral da produção histórica mundial ao longo dos tempos sugere que os historiadores profissionais não estabelecem, sozinhos, o enquadramento narrativo no qual se encaixam as suas estórias. Mais frequentemente, alguém já entrou em cena e estabeleceu o ciclo de silêncios. (TROUILLOT, 1995, p. 26, tradução nossa $)^{4}$

\section{Introdução}

Neste artigo propomos que, na contemporaneidade dos regimes políticos democráticos e defensores dos direitos humanos, a eficaz reprodução de relações de poder com base na "raça" resulta de um jogo de in/visibilização - ancorado no Eurocentrismo - que, por um lado, ativa imaginários e práticas excludentes, e, por outro, naturaliza as configurações de poder que as sustentam - isto é, naturaliza uma "história de poder" específica (QUIJANO, 2007, p. 168). Assim, discutiremos aqui este processo analisando como, nos discursos políticos e no contexto educativo português, o racial se insere neste jogo de in/visibilidades, sendo considerado como resultante da presença do "outro" da colónia e, logo, naturalmente irrelevante para a formação do espaço nacional-metropolitano e, de modo geral, para a formação da noção de "Europeidade". A partir dos discursos analisados, ilustramos a despolitização do racismo - com diferentes níveis de sofisticação - via a naturalização do colonialismo e a reificação do "imaginário imigrante" (SAYYID, 2004); neste sentido, o racismo é interpretado como algo que sucede aos outros - etnorracialmente marcados - mas que não diz respeito ao que "nós" somos, um "nós" que, aliás, nunca é questionado.

Assim, no seguimento de Lesko e Bloom (1998), sugerimos que o questionamento da epistemologia positivista por trás destes pressupostos requer uma abordagem informada historicamente que conceba "raça" e racismo como fenómenos políticos emergindo de situações históricas, isto é, "raça"/racismo como elementos fulcrais dos projetos dos estados modernos, das tecnologias de governância (pós-)colonial (FANON, 1952; CÉSAIRE, 1955; GOLDBERG, 2002; HESSE, 2004; LENTIN, 2008). Nesse sentido, contestamos a noção (historicista) dominante de racismo como resultante de ideologias retrógradas,

${ }^{4}$ Original: “And an overall sketch of world historical production through time suggests that professional historians alone do not set the narrative framework into which their stories fit. Most often, someone else has already entered the scene and set the cycle of silences." 
irracionais e extremistas que teriam sido superadas, ainda que se admita que possam hoje ressurgir em contextos de crise sociopolítica e económica, na forma de "surtos racistas" bem localizados ou de supostos "delírios de indivíduos racistas" (BALIBAR, 1988, p. 58-59).

Este artigo está dividido em três seções. Em primeiro lugar, iremos mostrar como se tem consolidado a presente ausência do racial, isto é, como se tem constituído um ciclo de silêncios e consensos sobre o racial na própria ação de combate ao racismo - marcada pelo antirracialismo - de organizações globais como a UNESCO. Examinaremos ainda como a dissolução do racial está a ser produzida através da associação entre racismo e imigração no contexto europeu contemporâneo, tanto na política como na academia. Em segundo lugar, incidindo sobre o trabalho empírico e análise de livros didáticos de história contemporâneos que realizámos em Portugal, iremos mostrar como, nos debates sobre a história e, mais concretamente, sobre o ensino do colonialismo e da escravatura se tem esvaziado a sua relevância política e evadido o racial para compreender a chamada escravatura Atlântica dos séculos XV ao XIX. Por fim, concluímos com uma análise dos contornos daquilo a que denominamos o "consenso (pós-)colonial" em Portugal, inserido num contexto mais amplo de esvaziamento da plausibilidade de um vocabulário que dê conta do racial/ racismo nas sociedades contemporâneas.

As reflexões que aqui apresentamos baseiam-se num projeto de investigação que tem como título “"Raça' e África em Portugal: um estudo sobre manuais escolares de história (2008-2012)". ${ }^{5}$ Este é um projeto interdisciplinar que tem como objetivo explorar a construção do eurocentrismo considerando os diversos contextos de produção, circulação e consumo dos livros didáticos. Tomando uma abordagem ampla face à educação e à história, o trabalho empírico do projeto dialogou com uma diversidade de atores envolvidos neste campo de relações de poder simbólicas (na academia, escola, estado, sociedade civil e média). Para analisar tais relações, trabalhámos sobre as seguintes linhas de investigação: 1) a produção e a disseminação do conhecimento histórico; 2) a ligação entre políticas públicas, curricula e livros didáticos; 3) a escrita e produção dos livros; 4) a pragmática do ensino escolar; 5) a participação da média e de organizações da sociedade civil em debates relevantes.

Quanto à investigação realizada, duas notas prévias são necessárias. Em primeiro lugar, relativamente à seleção e uso dos livros didáticos. Em Portugal, os livros didáticos devem seguir as orientações curriculares do Ministério da Edu-

5 “"Raça'e África em Portugal: um estudo sobre manuais escolares de história” é um projecto financiado pela Fundação para a Ciência e a Tecnologia (ref. FCOMP-01-0124-FEDER-007554). Mais informações: <www.ces.uc.pt/projectos/rap $\geq$. Acesso em: 10/07/2012. 
cação, sendo o recurso pedagógico mais utilizado na sala de aula, constituindo assim o curriculum de facto (CRUZ, 2002). No projeto, a nossa análise incidiu sobre os livros didáticos de História das cinco linhas editoriais mais vendidas em Portugal no ensino obrigatório (mais particularmente no $3^{\circ} \mathrm{Ciclo}$, destinado a crianças dos 12 aos 15 anos de idade aproximadamente) no ano lectivo de 2008-2009. Os livros de História foram analisados de forma sistemática, através de uma abordagem crítica à análise de conteúdo.

Abordando a escola como estando no epicentro de importantes debates políticos, culturais e sociais, e seguindo autores como Teun van Dijk, que propõem o estudo "das estruturas e processos subtis do racismo moderno" (1993, p. 254), o projeto dialogou com os contextos de formação e circulação dos discursos. Nesse sentido, foram realizadas entrevistas em profundidade, grupos de discussão e workshops interativos com quase 60 participantes de diversos perfis profissionais (designadamente, historiadores, docentes e estudantes universitários, editores, autores, decisores políticos, representantes de associações de pais e organizações sociais, jornalistas, professores e estudantes).

Em segundo lugar, deve mencionar-se que a escravatura e o seu ensino - um dos focos deste artigo - tem ocupado um lugar relativamente marginal em Portugal, constituindo de certa forma um parêntesis numa narrativa mais ampla que celebra o "pioneirismo" da Expansão portuguesa. ${ }^{6}$ Assim, iremos explorar aqui como se constitui, através dos livros de História, uma narrativa que conduz ao esvaziamento da relevância política da escravatura (TROUILLOUT, 1995) e, sobretudo, ao apagamento da governamentalidade racista a que esteve associada (HESSE, 2002), sendo incapaz de questionar, de forma mais ampla, a persistência do racismo nas sociedades contemporâneas pós-coloniais. Ainda que tenha havido um crescente interesse pela questão da escravatura no contexto europeu - visível em iniciativas relativas a debates mais amplos sobre história, identidade nacional e multiculturalismo ${ }^{7}-$, simultaneamente tem sido obscure-

${ }^{6}$ Ver, por exemplo, Roberto Carneiro, em: COSTA, J. P. O.; LACERDA, T. A interculturalidade na expansão portuguesa (Séculos XV-XVIII). Lisboa: ACIME, 2007.

${ }^{7}$ É preciso salientar aqui que esta diversidade de debates político-académicos está ancorada em diferentes interrogações e lutas políticas e, portanto, responde a distintas posições de poder. Neste sentido, Nimako e Willemsen (2011) distinguem quatro tipos de tendências/movimentos em nível global: (i) o movimento de recordação e comemoração iniciado pelas comunidades negras desde o momento em que a escravatura foi legalmente abolida; (ii) o movimento de reparações, também promovido sobretudo por comunidades negras; (iii) os aniversários e pedidos de desculpas, iniciativas geralmente em nível dos estados e governos; e (iv) a construção de museus e planeamento de exibições, uma tendência promovida pelas elites e que incide sobretudo nos artefactos, infraestruturas, heranças culturais e arquitectónicas (NIMAKO; WILLEMSEN, 2011, p. 7). Sobre as diferentes narrativas, memórias e histórias públicas ver também: Nimako e Small (2010); Vergès (2010). 
cida a ligação entre colonialismo, escravatura e racismo (GOLDBERG, 1993; HESSE, 2004). No contexto português, a nossa própria investigação tem sugerido que os discursos políticos, académicos e pedagógicos têm sido marcados pela despolitização do colonialismo (ARAÚJO; MAESO, 2010) e a evasão de um debate sobre o racismo (MAESO; ARAÚJO, 2010), como veremos em seguida.

\section{Estabelecendo o ciclo de silêncios/consensos: antirracialismo e conhecimento do "outro"}

A primeira metade do século passado foi cenário de uma viragem nos discursos e projetos políticos de vários contextos europeus e norte-americanos: "da celebração da superioridade à aceitação da igualdade racial" (FÜREDI, 1993, p. 5). Esta viragem foi fruto das ansiedades perante a "erosão das certezas raciais" e o costumeiro "medo de vingança racial" que o crescente poder de mobilização política dos projectos anticoloniais colocava às elites ocidentais (FÜREDI, 1993, p. 17-20). O medo das consequências da desestabilização do status quo que legitimava a superioridade do "Ocidente" impulsionou a rejeição da validade de teorias e políticas raciais, tomando forma na crítica ao "racismo científico" - entendida sobretudo como uma crítica à "manipulação política" do conhecimento científico, sendo o Nazismo o exemplo extremo. Foi neste contexto que, nos anos 50 e 60, a UNESCO emitiu várias declarações sobre a chamada "questão racial" com o intuito de combater o preconceito racial (UNESCO, 1969). Nessas declarações, é notória uma crença na neutralidade do conhecimento científico, precisamente por se usarem os factos apurados pelo conhecimento científico para desacreditar o "conceito" de raça (por exemplo, UNESCO, 1951), obstando assim a uma análise política do envolvimento da academia na sustentação de ideias sobre o racial durante os dois séculos anteriores. Neste período, a UNESCO promoveu também diferentes projetos com vista ao combate do preconceito e da intolerância racial na educação (BIBBY, 1959; UNESCO, 1967), assim como de monitorização e erradicação de estereótipos nacionalistas e raciais nos livros didáticos - ações já desenvolvidas durante a primeira metade do século ao abrigo da Liga das Nações e outras organizações nacionais (UNESCO, 1949, 1962). Estas iniciativas vieram mostrar, por um lado, a falta de consenso entre os peritos académicos - principalmente nos campos da sociologia, da antropologia cultural e da antropologia física, da biologia e da genética - sobre os "factos científicos" que deveriam sustentar qualquer discussão sobre estas temáticas (UNESCO, 1952); por outro, a esterilidade política 
de um debate centrado na desacreditação científica do conceito de "raça" e de um entendimento do racismo e da discriminação racial baseada no preconceito e nos aspectos socioeconómicos que o sustentariam.

O que nos parece problemático nestes debates e iniciativas é que as discussões sobre "raça" têm incidido sobre o seu estatuto enquanto "conceito" e interpretado racismo enquanto "doutrina" que justificaria as desigualdades e discriminações - centrando-se no referido "racismo científico" do período 18501930. A nossa crítica vai mais além e propõe que "raça" e racismo devem ser analisados como ideias e fenómenos histórico-políticos da modernidade, isto é, como parte fundamental da constituição do Eurocentrismo como paradigma de produção de conhecimento que caracteriza o projeto da modernidade e as suas pretensões de universalidade a partir de finais do século XV (DUSSEL, 1993, 2000; WALLERSTEIN, 1997; QUIJANO, 2000; SANTOS, 2007) e, portanto, da formação do capitalismo, dos estados-nação, do colonialismo e da ideia de "Europa". Porém, no meio internacional, as relações entre colonialismo e racismo por um lado, e entre racismo e a ideia de "Europa" e "Ocidente" por outro, têm sido silenciadas através de uma leitura despolitizada que interpreta o racismo como uma questão de reprodução de estereótipos/preconceitos e atitudes etnocêntricas e raciais (por exemplo, UNESCO, 2004, p. 73, 94). Um dos principais efeitos desta formatação da discussão académico-política e pedagógica foi a proclamação da gradual obsolescência de "raça" e do lugar marginal do racismo nas sociedades ocidentais - isto é, a redução do antirracismo ao antirracialismo (GOLDBERG, 2009, p. 1): assim, o racismo circunscreve-se a situações de "excesso de pensamento racial" (HESSE, 2004, p. 20-21) e o antirracismo ao combate a esses excessos via um maior conhecimento do (contacto com) "outro" - isto é, as minorias, os imigrantes, as culturas não ocidentais.

Nesta perspectiva, é interessante examinar como em alguns contextos europeus tem sido construído, sobretudo nas últimas duas décadas, um certo consenso político e académico em torno da associação entre racismo e imigração, que favorece a dissolução do racial. Isto é, a ideia do racismo como uma natural reação à presença do outro imigrante - um discurso com enorme visibilidade nos contextos nacionais contemporâneos descritos como "países de nova imigração" (ex. Espanha, Portugal, Dinamarca, Itália). No contexto português, tal é evidente se tomarmos como principal objeto de análise as publicações resultantes de dois grandes eventos político-académicos sobre estas temáticas: o I Congresso "Imigração em Portugal: Diversidade, Cidadania e Integração? foi organizado pelo ACIME a 18 e 19 de dezembro de 2003 (ACIME, 2004); outro evento ilustrativo destas relações entre academia e política de estado foi o chamado Fórum Gulbenkian "Imigração - Oportunidade ou Ameaça?" e tomou lugar a 6 e 7 de março de 2006, com o apoio do ACIME e da Fundação Calouste 
Gulbenkian(VITORINO, 2007). Estes eventos são particularmente interessantes por colocarem em diálogo as esferas da política (institucional e partidária) e da academia. Promovidos pelo então Alto-Comissariado para Imigração e Minorias Étnicas (ACIME, atualmente ACIDI - Alto-Comissariado para Imigração e Diálogo Intercultural), ${ }^{8}$ tais debates ajudaram a configurar a imigração como um tema político central. Consequentemente, no discurso e prática política do ACIDI privilegia-se uma concepção do racismo e da xenofobia como a derivação de uma deficiente integração das comunidades imigrantes e das minorias étnicas. O seu próprio âmbito de atuação pode ser visto como uma espécie de movimento pendular entre a necessidade do conhecimento do "Outro" da parte da sociedade maioritária e de favorecer uma ativa integração na sociedade "autóctone", principalmente na esfera económica e na cultural. Neste quadro, uma abordagem antirracista não é considerada prioritária. É a integração bem-sucedida (geralmente lida como assimilação) das comunidades imigrantes e das minorias - consideradas mais vulneráveis perante a discriminação racial - que é tida como o antídoto natural contra o racismo. Nos discursos dos diferentes comissariados, as práticas de discriminação racial que são tidas como inerentes às estruturas sociais e que, portanto, condicionam a vida quotidiana (por exemplo, não obter um emprego, não conseguir alugar uma casa), são rotuladas como "racismo subtil", 9 sem no entanto se aludir às configurações institucionais que produzem esses obstáculos invizibilizados. Esta abordagem naturaliza o "facto" de serem os "imigrantes" ou os "ciganos" as principais vítimas da discriminação racial e favorece o lugar marginal do antirracismo nas políticas públicas, considerando que é "pelo lado positivo", quer dizer, pela "ativa integração" dos imigrantes e das minorias, que o "preconceito" será eliminado.

Neste quadro, o racismo acaba por ser naturalizado como uma reação à diferença (associada à figura do imigrante) e como uma consequência da ignorância de certos grupos sociais. ${ }^{10}$ Assim, as esferas da academia e da política institucional e partidária são geralmente ilibadas da sua produção e perpetuação, confirmando a convicção de que a opinião pública desinformada constitui o sector da sociedade onde residem os preconceitos, e a educação seria, portanto, um lugar privilegiado para a sua "correção" e "compensação", através da

${ }^{8}$ Ver em: <www.acidi.gov.pt>. Acesso em: 10/07/2012.

${ }^{9}$ Ilustrativos da centralidade desta ideia na academia são os estudos coordenados por Jorge Vala e colegas (1999), ancorando-se no trabalho de Thomas Pettigrew e Roel Meertens sobre o preconceito, no âmbito da Psicologia Social.

${ }^{10}$ Daí que uma das principais estratégias de combate ao racismo seja a apresentação de informações capazes de contrariar os mitos erróneos que circulam sobre populações imigrantes e minorias, como, por exemplo, a brochura Imigração: os mitos e os factos publicada pelo ACIME (2005). 
inclusão das perspectivas do "outro", um aspecto reiterado pelos historiadores e professores entrevistados:

Eu penso que desafio mesmo no próprio ensino da história tem que se ajudar os alunos a terem a percepção de que há outras visões, de que há outros olhares, que o facto de os outros terem olhado a pensamentos diferentes dos nossos, isto não quer dizer nem que os nossos são melhores nem que os nossos são piores, temos de encontrar plataformas de entendimento porque é possível ter opiniões diferentes e partilhar espaços... (HISTORIADORA 01).

Nós temos aqui sempre a visão do europeu sobre África e nunca temos a visão de África propriamente dita. [...] Nós não temos visão do africano, é muito raro... (HISTORIADORA E PROFESSORA NO ENSINO SECUNDÁRIO).

Assim, entende-se que o principal problema é como a historiografia e a didática da história podem atender à crescente diversidade das sociedades nacionais e, portanto, à(s) história(s) das minorias. Aqui, o lugar de Portugal costuma ser retratado de forma ambivalente, pois se assume que a sua história teria trazido uma maior sensibilidade sobre essas outras histórias, apesar de simultaneamente não conseguir escapar a uma problemática tida como mais geral:

[Uma sociedade entendida como cada vez mais diversa] coloca à historiografia o facto de qualquer manual dever atender, deve ter em conta essa própria diversidade; quer dizer, esta ideia que se fala: a "História Universal", a "História Universal" não existe, não existe, compreende? [...] Eu pessoalmente entendo que é um desafio muito forte e muito grande à realidade dos manuais portugueses ou dos manuais espanhóis, ou dos manuais alemães ou dos manuais etc. Agora também nós... a minha experiência diz-me que nós, apesar de tudo, pensamos mais neste problema do que pensam outros países... A América... Os manuais americanos são muito mais americanos do que os nossos manuais são portugueses. Eu acho que é [...] a esses desafios, a que nós devemos responder e que devia originar um grande debate sobre isso que não existe, mas outra coisa é pensar que nós neste aspecto não estamos alertados para esta situação e, por outro lado, a nossa prática é uma prática mais nacionalista do que é a prática de qualquer outro país, a 
Alemanha ou a Inglaterra ou a Espanha ou a América? [...] Quer dizer, isso é um problema que existe, não é nosso. É um problema geral que existe (HISTORIADOR 02).

\section{Ressonâncias pedagógicas: escravatura e "raça"/racismo nos livros didáticos de História}

[relativamente ao processo de avaliação dos manuais] O processo ainda não está terminado mas, aquilo que podemos verificar é que da leitura dos projectos de relatório final não se sente que os manuais avaliados induzam a discriminações, nomeadamente no que diz respeito à raça, no que diz respeito às questões do eurocentrismo (Decisora política na área da educação).

A educação - vista como uma esfera tanto de homogeneização como de transformação social - e mais particularmente os curricula constituem objetos privilegiados para analisar como se materializam os discursos públicos sobre o racial. Concretamente, quando consideramos a produção de livros didáticos de história do $3^{\circ}$ Ciclo no contexto português, parece-nos que se concretiza a institucionalização deste silêncio discursivo em torno de "raça" e "racismo", constituindo as narrativas dos livros sobre a escravatura um caso paradigmático da operação de in/visibilização do racial. Para esta eficaz in/visibilização no ensino da escravatura, contribuem de forma fulcral duas fórmulas narrativas: a) a naturalização do sistema de escravatura e a objetificação da figura do escravo; b) a inscrição da escravatura numa abordagem individualizadora e moralizadora que garante o triunfo do humanismo igualitário.

Relativamente ao primeiro aspecto, a forma como a escravatura é apresentada nos livros analisados insere-se, a nosso ver, numa abordagem despolitizada mais ampla de vários processos históricos (designadamente a cristianização e o colonialismo, com os quais está interligada), removidos da esfera das relações históricas de poder que os constituíram (BROWN, 2006, p. 15). A trivialização da escravatura é conseguida através da sua descrição como um aspecto "natural" do contexto de "expansão" (económica) europeia e portuguesa dessa época. A escravatura surge assim como mais um elemento das rotas comerciais e, portanto, das "necessidades económicas" nascidas com a colonização. Como nos diz Ellen Swartz (1992, p. 345) "o discurso da escravatura [...] serve geralmente 
para justificar e normalizar o sistema da escravatura". Este é visto, assim, como uma necessidade, e não como uma escolha, "implicando que a escravatura era natural, inevitável e inalterável" (SWARTZ, 1992, p. 345). Assim apresentada como parte da "circulação de novos produtos" entre a Europa e outros continentes, surge como natural a objetificação da figura do escravo, geralmente descrito como mais uma mercadoria colocada em circulação pelos poderes coloniais: "importados" (LH8-1, p. 46), "reexportados" (LH8-1, p. 38), "partiram [...] com destino à Europa ou à América" (NH8-1, p. 38), foram parte da "circulação de produtos e pessoas" e do "movimento de povos" (LH8-1, p. 46). ${ }^{11}$ Estas descrições contribuem para a efetiva invisibilização da violência deste sistema político-económico, uma tendência que se tem acentuado recentemente.

Nesta abordagem dominante, enfatiza-se cada vez mais a ideia da universalidade da escravatura como modo de exploração económica e a sua trivilialização pelo facto de já acontecer em certas regiões e ser praticada por outros "povos" (por exemplo, os árabes). Assim, o ensino de uma certa abordagem é assumido como neutro, isto é, o mero "ensinar os factos" que incidem num jogo de apuração e partilha da culpa original (HIRA, 2012; ver também VAKIL, 2006, p. 80), naturaliza-se a escravatura como um sistema universal de exploração:

[...] a escravatura sempre existiu em África, os portugueses participaram nesse processo e potencializaram-no e expandiram-no, sim senhor! Mas ele sempre existiu. Lá como os portugueses todas as potências europeias que estiveram em África estiveram envolvidas nisso e a escravatura continua a existir em África, infelizmente. Portanto há sim senhor que denunciar, denunciar... [...] mas também não se pode assumir todas as culpas, não é? (HISTORIADOR 03).

[...] uma coisa que nunca se pode esquecer quando nós passarmos nessa matéria e que é o seguinte: o escravo foi, neste caso o africano, "coitadinho do escravo... Ah, coitados, ser escravo não devia ser fácil..." Mas não nos podemos esquecer que quem os transformou em escravos foram os próprios conterrâneos deles, eles não viviam... Como é que eu vou explicar isto? Os barcos chegavam a África... Os barcos chegavam a África e os barcos não entravam por África adentro para irem buscá-los.

\footnotetext{
${ }^{11}$ Não obstante, numa versão anterior de um dos manuais, surge uma descrição que alude à violência do tráfico: "deram-se grandes migrações: de europeus para a América e outros continentes, enquanto escravos africanos negros eram levados à força para o território americano." (VH8, p. 28, ênfase nossa).
} 
Eles eram trazidos de dentro para as costas, e quem é que os trazia? Quem vivia com eles e já os tinha transformado [em escravos] (ESTUDANTE UNIVERSITÁRIO, grupo de discussão).

Perpassa também os livros didáticos analisados uma narrativa moralizadora e individualizadora da escravatura, incidindo principalmente sobre as "condições degradantes" em que os escravos viviam (LH8-1, p. 39; VH8, p. 63-65) e o seu "sofrimento", retirando às suas "vítimas" qualquer capacidade de ação política. Ou seja, enfatiza-se a "desumanidade" da escravatura, mas sem uma abordagem política que permita vincular ideologias raciais a processos económicos e culturais, nem imaginar a sua contestação. Assim se constrói o triunfo do humanismo igualitário: para abordar o desafio à injustiça e a estruturas socioeconómicas e culturais violentas é projetada a liderança de benevolentes "espíritos europeus" (isto é, "membros do clero", como o Padre António Vieira ou Bartolomeu de las Casas), e mascara-se a sua imersão no sistema colonial através da higienização do papel das missões e dos projetos de "evangelização" na configuração de ideologias raciais. Tal é evidente no seguinte excerto de uma entrevista com um historiador:

Mas é que eu penso que nós não temos de ter uma postura moral sobre... Quando estamos a trabalhar a escravatura, seja o império romano, seja o que for, a escravatura implica um determinado... Nós podemos entrar para relativizar, ou seja, nós devemos ser capazes de perceber o que é a escravatura à luz do contexto histórico e humano em que a escravatura ocorre, e aí devemos fazer um exercício de empatia, de facto. Mas não podemos retirar a carga política, económica que a escravatura tem... [...] e convém, sobretudo, que nós pensemos o que é que significa, em termos de desenvolvimento de pensamento humano, pensar que determinadas pessoas porque são diferentes, não são pessoas e isto não é uma questão de moralidade, isto é uma questão de ética, diria eu. Também é importante que os alunos percebam o quadro mental que explica, por exemplo, o célebre debate com o Padre Bartolomeu de Las Casas em que ele defendia que os índios tinham almas. Essa ideia de que há uns seres que parecem humanos mas não são; portanto é preciso debater se eles terão ou não terão alma. É esta questão que é importante que eles percebam, muito mais do que o julgamento de que é bom ou que é mau - "parece-te bem que houvesse escravos?" (HISTORIADORA 01). 
Apesar da crítica aparente a uma abordagem moralizadora da escravatura, a institucionalização de uma "memória" específica do combate à escravatura acaba por ativar a centralidade da ação preconizada pelos atores de uma história moral cristã e, concomitante, por apagar as lutas políticas e rebeliões dos escravos. Nesta concepção, desenha-se uma linearidade da história que estabelece a Revolução Francesa como berço do antirracismo, tendo como pilares fundamentais a "liberdade pessoal" e a "igualdade de todos os seres humanos", e que perpassa todos os livros analisados.

Estas duas fórmulas narrativas contribuem para a construção da invisibilidade do racismo e da ativação concomitante de "raça". Nos livros analisados, não se apagam tanto os seus contornos raciais como se deixam antes a nível implícito, naturalizando a dominação de base racial: "escravos negros" (LH8-1, p. 39, 96), "negros" (LH8-1, p. 39), "escravos negros africanos (LH8, p. 28) ou "escravos africanos" (LH8-1, p. 39; VH8, p. 62, 64) são expressões que sugerem o culminar de um processo de tornar equivalente as ideias de "escravo" e "negro", sem nunca discutir a sua base racializada. Quando esta discussão foi colocada nas entrevistas realizadas, é interessante notar como a concepção de "raça" é vista como uma importação do pensamento britânico ou francês:

A experiência colonial portuguesa dos séculos XVII e XVIII... por exemplo, temos aqui em postdoc uma americana de origem indiana, está a estudar a maneira como no século XVII começou a circular no Estado da Índia um discurso racista baseado na... na medicina... para provar que a raça dos trópicos é mais mole, é inferior às pessoas da Europa. Mas este é o mesmo discurso que os holandeses têm em relação a nós da Europa do Sul, se pensarmos bem... é o mesmo discurso, tal e qual... e portanto, e ela está a notar que o discurso entra no império português por influência inglesa, por influência inglesa. Portanto não é um discurso natural do império português [...] (HISTORIADOR 04).

Tal discussão ajuda a consolidar a noção de que "raça" é, portanto, uma ideia relativamente anómala e tardia no contexto português: ${ }^{12}$

${ }^{12}$ Significativamente, apenas um dos participantes entrevistados estabeleceu a relação entre racismo e escravatura atlântica: "[...] se nós virmos na história, recuarmos no tempo, os escravos, ao serem vendidos nas feiras, eram negociados como negros, não é? As pessoas utilizavam o mesmo termo, isso seria um sinónimo de escravo...” (Estudante universitário). 
Agora, de facto a questão do ponto de vista do estatuto científico da raça é uma questão do século XIX [...]. Digamos que quando as questões da raça estão em grande discussão, essa ideia da raça também, desse discurso, desse debate científico, desse debate científico... provavelmente poderemos situá-lo no século XIX... (HISTORIADORA 01).

[...] a ideia que eu tenho é que na Idade Moderna não havia um pensamento jurídico estruturado em relação ao problema da presença da população africana negra, e eu julgo que esse problema só aparece no século XIX, verdadeiramente, de forma estruturada, verdadeiramente no século XIX. Até porque os negros em Portugal são vistos como mão de obra, mão de obra escrava mas, também é verdade que a partir de certa... sobretudo no Alentejo, no Ribatejo, a partir de certo momento vai haver mistura e cruzamento entre africanos e europeus, entre negros e brancos. E essa população negra, sobretudo no Alentejo, acaba por ser absorvida. Isto significa que nada obsta, nada obsta, ao cruzamento, ao cruzamento entre negros e brancos. Portanto, curiosamente aquilo que me parece é que o problema negro nasce em Portugal com a questão dos judeus e só muito mais tarde, a partir do século XIX, mas isto é uma ideia, posso eu estar errado, é que de facto começa a haver uma teorização de inferioridade do negro... [...] Só, portanto, ao longo do século XIX começa a haver legislação que tende à criação de categorias diferentes... de base racial. E isso vai culminar a aprovação do estatuto indígena e isso estabelece, de facto, o estatuto do cidadão e o de súbdito colonial, o indígena. (HISTORIADOR 03).

Porém, ainda antes da existência de um conceito preciso de "raça", as noções e práticas da administração de populações assentes em ideias raciais já vigoravam na Península Ibérica do século XV para se referirem a grupos de seres humanos (FREDRICKSON, 2002), como evidente na construção do "negro" enquanto sinónimo de escravo (SWEET, 2003, ver também TINHORÃO, 1988). ${ }^{13}$ Isto é crucial para a análise da escravatura nos livros de História portugueses pela forma como neles se reduz o racismo a certos momentos da história do colonialismo, designadamente ao "novo imperialismo" do Século XIX (LH9-1, p. 14), impulsionado pela “cobiça pela África” e a "missão civilizadora" (enfatizando os casos britânico e francês). Esta ligação permite, de forma eficaz, que os livros não precisem de considerar a relevância das ideologias e

${ }^{13}$ A ideia de "raça", aliás, perdura nos manuais, sobretudo quando se trata da escravatura e miscigenação (ex: RH8, p. 28; VH8, p. 31). 
governamentalidades raciais da "expansão" portuguesa. O facto de o racismo (não) ser nomeado através do eufemístico "sentimento de superioridade" impede a sua consideração como uma forma de "governamentalidade rotineira" (HESSE, 2004) que estrutura o social e o político para além da existência de uma doutrina apoiada no conhecimento "científico". Pelo contrário, no seguimento do proposto por David Theo Goldberg, o período histórico designado atualmente como "expansão" ou "descobrimentos" deve considerar-se decisivo para a configuração de classificações e governamentalidades racistas:

O Século XVI marca assim a viragem no aumento da consciência racial. Não apenas o conceito de raça passou a ser aplicado explicitamente e conscientemente, como se começa a ver emergir a caracterização racial tanto na arte como nos debates político-filosóficos. [...] enquanto a escravatura pode ser amplamente explicada (mas de modo algum exaustivamente) em termos económicos, deve insistir-se em perguntar por que é que foi nesse momento que a diferença racial veio definir a aptidão para a escravização e por que alguns tipos de diferença racial e não outras (GOLDBERG, 1993, p. 203, tradução nossa). ${ }^{14}$

É neste sentido que autores como Barnor Hesse (2002) ou James Sweet (2003) têm utilizado a expressão "escravatura racial", precisamente para dar conta da saliência do racial na escravatura atlântica entre os séculos XV e XIX. ${ }^{15}$

Pelo contrário, nos livros didáticos analisados predomina antes uma narrativa que considera os "aspectos positivos do colonialismo", numa lógica que assume que os processos históricos podem/devem ser desagregados analiticamente, com base nas consequências positivas e negativas que trouxeram. Esta operação está ancorada na ideia de que a modernidade, e concretamente a chamada "expansão", foi um triunfo (WALLERSTEIN, 1997, p. 94-96, 102103), mas sem esquecer as suas consequências "negativas" - como a escravatura.

${ }^{14}$ Original: "The sixteenth century thus marks the divide in the rise of race consciousness. Not only does the concept of race become explicitly and consciously applied but also one begins to see racial characterization emerging in art as much as in politico-philosophical debates. [...] while slavery may be explained largely (though not nearly exhaustively) in economic terms, one must insist in asking why it was at this time that racial difference came to define fitness for enslavement and why some kinds of racial difference rather than others."

${ }^{15}$ É de considerar que, no caso português, a escravatura teve também uma importante dimensão no Índico e que formas de trabalho forçado perduraram até á década de 1960 (ver, entre outros, MENESES, 2010). 
Assim, a presente despolitização de processos como o colonialismo e o racismo tem facilitado a interpretação da escravatura na semântica "multicultural" - em termos de miscigenação, no caso do Brasil, e de "contacto cultural", no Portugal metropolitano. Neste contexto, os manuais ajudam a validar o vocabulário e a lógica coloniais, assumindo acriticamente a divisão entre as "raças" passivveis de ser escravizadas - o negro - (SWEET, 2003, p. 5-7) e os povos indígenas, inseridos no espaço da política com certa capacidade de ação, ainda que tenham de ser "defendidos" e "abrigados" pelos membros do clero. Esta narrativa reforça a construção do escravo enquanto sujeito incapaz de ação política, e evita o debate "raça"/poder consignando o fenómeno da escravatura à figura de um "mal" passado, efetivamente superado. Assim se garante a ideia da "Europa" e do "cidadão europeu" como motores da história e da política, ignorando que, em grande medida, a abolição da escravatura se deveu à ação política dos escravos e a longos processos de rebelião e resistência. Neste sentido, deve ser notado como a Revolução de Saint-Domingue (1791-1804), atual Haiti - um processo fulcral na história do colonialismo e das lutas políticas das populações negras escravas $^{16}$ - tem sido silenciada na historiografia europeia e nos livros didáticos (TROUILLOT, 1995, p. 95-107). ${ }^{17}$ Igualmente, é extremamente ilustrativo que os manuais portugueses atuais geralmente não façam qualquer referência aos quilombolas, designadamente ao Quilombo de Palmares (na capitania colonial de Pernambuco), um dos principais focos da resistência escrava desde o século

\footnotetext{
${ }^{16}$ A revolução e a declaração de independência do Haiti, de enorme repercussão no pensamento revolucionário francês do século XIX, levantaram questões fundamentais sobre o nível de igualdade e inclusão admitidas pelo pensamento liberal face à “questão colonial e racial", embora tal não seja geralmente reconhecido na historiografia. Anna Julia Cooper (1858-1964), a primeira mulher negra a doutorar-se pela Universidade de Paris-Sorbonne, em 1925, com um trabalho pioneiro sobre as relações e controvérsias entre os políticos revolucionários em Paris e as elites coloniais em Haiti e os seus representantes, evidenciou a fundamental contradição entre o ideário revolucionário e os fundamentos do colonialismo, principalmente da escravatura (COOPER, 2006, p. 59-70). Numa outra perspectiva, Du Bois examinou na sua tese de doutoramento - publicada em 1896 - a relevância fulcral da revolução em Haiti para compreender as mudanças legislativas em torno da abolição do comércio de escravos nos estados do sul dos Estados Unidos entre 1791 e 1806 (DU BOIS, 2007, p. 70-93).

${ }^{17}$ Este silêncio refere-se não tanto à ausência de menção a este momento da história de lutas contra o colonialismo, mas no modo como a inclusão de certos momentos da história é contida numa narrativa mais ampla que revela a persistência do Eurocentrismo. Por exemplo, ainda que recentemente a Revolução do Haiti seja abordada em alguns contextos anglo-saxónicos, particularmente no contexto britânico após as comemorações da abolição da escravatura em 2007, a sua significância política é por vezes contida por narrativas que estabelecem o Haiti como um dos territórios onde ainda hoje persiste a escravatura (ver, por exemplo, os livros didáticos produzidos pelo School History Project: CULPIN et al., 2009, p. 87-88).
} 
XVII na região. Pelo contrário, a alusão aos modos de vida dos escravos, com a imagem "Escravos negros, dançando num dia de festa" - ajudam a reproduzir o imaginário racista dos séculos XIX e XX, e em particular do escravo, se não feliz, pelo menos resignado com a sua condição.

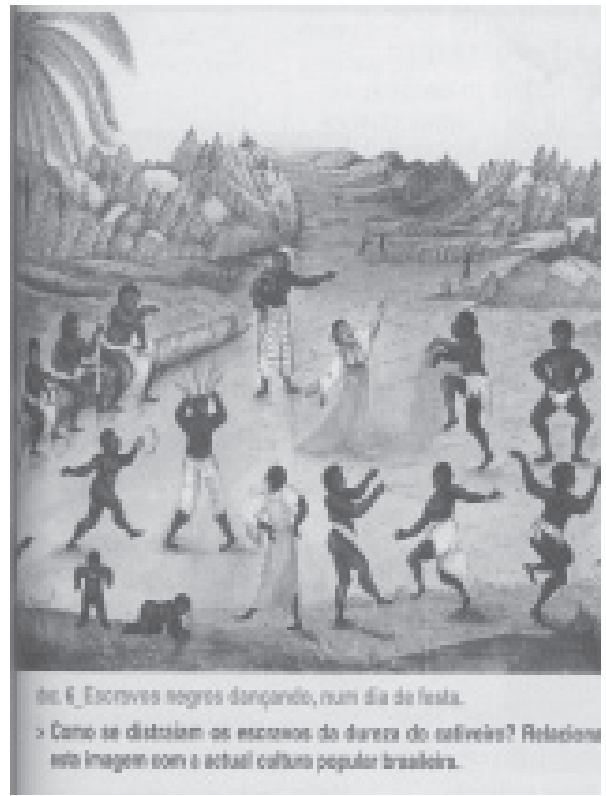

Figura 1 - "Escravos negros dançando, num dia de festa" (LH8-1, p. 99)

\section{Os contornos da construção do consenso (pós-)colonial}

Ainda que "raça" e racismo se tenham tornado duas ideias mal-amadas, as suas configurações atuais continuam definitivamente entrosadas nas estruturas sociopolíticas das sociedades ditas democráticas. "Raça" está, assim, "enterrada viva" (GOLDBERG, 2009, p. 1-31) num tempo de "racismos sem racismo" a que se tem convencionalmente designado como pós-racial - marcado pela "(re-)institucionalização do racismo privatizado, e a privatização dos racismos institucionalizados" (GOLDBERG, 2009, p. 362). Neste contexto, o vocabulário que pode dar conta do racismo para além de atos exacerbados pelo "desconhecimento" do "outro", por um ódio "irracional" ou por supostas "manipulações políticas" é cada vez menos plausível e está sempre submetido à comprovação 
da sua objetividade. Os desenvolvimentos ao nível das políticas e iniciativas na educação, e mais concretamente no ensino da história e das ciências sociais, confirmam este processo de esvaziamento de sentido de "raça" e racismo como fenómenos centrais para compreender a formação das sociedades contemporâneas e as suas estruturas políticas.

Assim, nos relatórios sobre os debates promovidos pelo Conselho da Europa (CoE) sobre o ensino da história europeia e a análise/revisão de livros didáticos entre 1953 e 1995 (CoE, 1995, 1996), nem a escravatura nem o ensino do racismo na história são mencionados; encontramos apenas uma recomendação (de 1958) que incide sobre a necessidade de "mencionar os lados positivos e negativos do colonialismo" (CoE, 1995, p. 20) ${ }^{18}$ e uma outra referência ao ensino das "Descobertas Portuguesas no ensino secundário da Europa Ocidental" e, de modo geral, sobre a "expansão europeia", alertando para a necessidade de "uma abordagem ponderada" que trate todas as consequências deste processo "de modo aberto e equitativo" (CoE, 1995, p. 50). ${ }^{19}$ Iniciativas e projectos posteriores no âmbito do Conselho da Europa têm apostado no multiperspectivismo como estratégia para superar uma história nacional/nacionalista, dominada por uma grande narrativa: promove-se o alargamento da história europeia, trazendo uma perspectiva global que inclua a questão colonial, e oferecendo espaço às diferentes perspectivas sobre um mesmo processo histórico (STRADLING, 2001, p. 141-151; 2006, p. iii, 7, 221-226). Porém, a análise da relação entre poder e conhecimento continua a ser evadida, e "raça" e racismo permanecem relegados à mera monitorização de estereótipos e preconceitos (STRADLING, 2001, p. 261), ou à promoção da empatia dos estudantes perante experiências de discriminação das minorias/imigrantes (STRADLING, 2001, p. 126, 248).

A evasão de uma discussão aprofundada sobre a relação entre poder e a produção de conhecimento como um elemento fulcral do ensino da história - e de todas as disciplinas - está ancorada neste fomento de narrativas ponderadas, equilibradas, com o intuito de oferecer visões da história a partir de outras perspectivas. Cabe perguntar-se, portanto, sobre os arranjos políticos que modelam a produção destas narrativas "ponderadas", arranjos estes cujos contornos específicos refletem os contextos particulares da sua produção. No caso português, assinalamos dois processos interligados que ajudam a regular a inclusão de outras perspectivas e o alargamento do conhecimento histórico, com especial repercussão nas narrativas sobre "raça", colonialismo e escravatura: em primeiro

${ }^{18}$ Conferência "The period from c.1870 to c. $1950 "$, Istanbul e Ankara, Turquia: 25 Agosto -3 Setembro 1958.

${ }^{19}$ Simpósio "Teaching about the Portuguese Discoveries in Secondary Schools in Western Europe", Lisboa, 1983. 
lugar, a predominância de uma narrativa mais ampla sobre a desejabilidade do consenso no ensino da história, de forma a manter a "paz social"; em segundo, a prevalência de uma visão securitária da identidade nacional num contexto contemporâneo visto como crescentemente multicultural.

(i) Apaziguar os antagonismos: uma pedagogia de "sensatez" e de "consenso"?

No trabalho empírico que temos realizado em Portugal, Eurocentrismo e racismo surgem como duas ideias desestabilizadoras, que têm o potencial de gerar divisões e conflitos sociais e pôr em causa a paz e a coesão da sociedade portuguesa. Nesse sentido, são vistas como ideias sectárias, que refletem os interesses de grupos particulares. Como sugere Frank Füredi (1992) na sua análise de debates sobre história e sociedade em contextos como o britânico, o alemão, o japonês e o norte-americano, "uma pluralidade de histórias tem sido aceitável para as elites no poder dentro dos limites da sala de aula, mas as demandas colocadas em nome de identidades em competição tendem a minar a coesão social" (FÜREDI, 1992, p. 10). Ainda assim, no contexto português, os debates sobre a pluralidade na história são geralmente formulados em termos de um confronto de histórias (legitimamente) nacionais - especialmente no contexto da atual construção do denominado espaço lusófono - assumindo e naturalizando a existência de uma perspectiva no seio da sociedade portuguesa. Assim, é nos antigos espaços coloniais, sobretudo aqueles no território africano - através da cooperação, no espírito de ajuda ao desenvolvimento -, que tem sido necessário negociar o consenso. Para criar estas narrativas consensuais, os entrevistados dão conta da capacidade de interferência nos textos de ensino adoptados nesses espaços:

[...] quando nós fizemos os manuais da $5^{\mathrm{a}}$ à $7^{\mathrm{a}}$ classe - manuais de português, estou a falar de manuais de português da $5^{\mathrm{a}}$ à $7^{\mathrm{a}}$ classe para Moçambique -, isto ocorreu nos anos 80, em que [a Ministra da Educação] pediu ao... nós fizemos uma missão em Moçambique, então como consultora da Fundação Calouste Gulbenkian e... ela apresentounos o projecto de manuais que estavam para sair para a $5^{\mathrm{a}}$ à $7^{\mathrm{a}}$ classe e pediu-nos que no fim de semana lhe déssemos a opinião sobre esses manuais. Nós fomos para casa, para o hotel, e começamos a ler aquilo e começamos a ficar arrepiados porque os manuais eram um grito de ódio contra os portugueses e o massacre do Quinchiti (quiti) e o massacre de mais não sei onde... quer dizer, o sangue escorria ao longo daquelas páginas. Nós ficámos numa situação bastante embaraçosa porque tínhamos de dar a nossa opinião e não queríamos que parecesse que estávamos a ser movidos por interesses nacionalistas... Mas, de 
qualquer maneira, o manual não só não era bom em termos literários como também era, como eu dizia, um regressar ao passado e um reavivar de feridas... Nessa perspectiva, quando na segunda-feira fomos dar a nossa opinião eu... Não era fácil de dar, até porque alguns dos autores de determinados textos eram os nossos interlocutores, portanto... era uma situação bastante difícil. De qualquer maneira a Ministra tomou uma atitude fantástica... fantástica: [...] "se vocês me aparecerem em Outubro... em finais de Outubro, princípios de Novembro, com uma nova versão dos manuais, eu comprometo-me em não publicar estes e em publicar aqueles que vocês me trouxerem". [...] penso que a história, naturalmente, será lida de uma maneira sempre diferente de um lado e de outro, não é?, e quando estamos a falar de fenómenos de colonização é evidente que este lado... um lado e o outro lado são bem diferentes, e olham para a história de uma maneira também diferente mas, tal como dizia o Miguel Torga, "O que fizemos de bom e de mau foi salgado na força das marés” e portanto não valerá a pena estar a espicaçar ódios antigos, não é?, e a fazer com que realmente esses ódios possam... possam criar situações de... de conflito (REPRESENTANTE DE ASSOCIAÇÃO DE PROFESSORES DE HISTÓRIA).

A vontade e a capacidade de intervenção sobre os curricula de antigos espaços coloniais são interpretadas em termos de maturidade política, baseando-se na naturalização e, portanto, na legitimação do colonialismo (i.e. existem leituras diferentes em ambos lados); o "bom senso" redimiria quaisquer supostos "interesses nacionalistas" nesta missão de cooperação e reforça-se assim - na construção alegadamente imparcial dos "dois lados" - o silêncio sobre o racial. Como sugere Hickling-Hudson (2006) relativamente ao discurso desenvolvimentista:

O silêncio sobre raça [como Sarah White (2002) propõe] é um silêncio cheio de implicações. Tanto mascara a sua centralidade para o projeto do desenvolvimento, como enfatiza a sua centralidade. [...] Os factos centrais no desenvolvimento são o capital internacional, blocos de poder regionais e a posição dos estados-nação, mas as suas metanarrativas e os seus pressupostos de superioridade têm contornos raciais (HICKLINGHUDSON, 2006, p. 204, tradução nossa). ${ }^{20}$

${ }^{20}$ Original: "The silence about race, White points out, is a silence full of implications. It both masks its centrality to the development project, and emphasizes this centrality. [...] The central facts in development are international capital, regional power blocs and the position of nation states, but its metanarratives and its assumptions of superiority have racial undertones." 
(ii) Em sociedades multiculturais, temos de ter orgulho: a construção de uma identidade nacional positiva

Um segundo aspecto a salientar é a prevalência da ideia de que a escola deve ser um lugar de valorização da identidade nacional, enfatizando a "expansão" como o período nobre da história da nação:

Bom, eu no tempo em que fui professor [de história no Liceu] seguia um pouco aquilo que os manuais indicavam e não estava propriamente em desacordo e não estava tão desperto nesse tempo para certas questões para as quais despertei apenas posteriormente. E portanto, eu achava que era... Naquele tempo, achava que, de certo modo, contribuía para a formação da cidadania no aluno uma certa glorificação daquilo que os portugueses tinham feito e que outros não tinham feito ou não tinham tentado sequer fazer. Portanto era uma aura de grandeza da qual enfim... que valia a pena aproveitar e transmitir. Eu hoje, apesar de tudo, não estou tão seguro que não seja assim (HISTORIADOR 05).

Portugal viveu há pouco mais de 30 anos um período colonial e nós se entramos aqui ... com dificuldades de falar sobre o assunto, entramos aqui numa... em algo que é depois não saber ultrapassar os erros, as coisas positivas, as coisas negativas... quer dizer, tem de se saber ler as coisas dentro da sua história, portanto acho que é um bocadinho isso... e portanto não...[...] não vejo nada de forma negativa o facto de se poder evidenciar aquilo que Portugal deixou espalhado pelo mundo (DECISOR POLÍTICO NA ÁREA DA INTERCULTURALIDADE).

No período convencionalmente designado por Portugal democrático, após Abril de 1974, começa a ser projectada uma "autêntica política ecuméni$\mathrm{ca}{ }^{21}$ que viria de certa forma responder à "crise" de uma identidade nacional geograficamente contraída com a "perda das colónias" em meados dos anos 70 (VAKIL, 2006, p. 81). AbdoolKarim Vakil sugere, neste sentido, que se deu "uma articulação entre a contracção física territorial e projecção global das suas relações com outros estados" (VAKIL, 2006, p. 81). Estes projectos políticos e as discussões que os envolveram - bem visíveis nos anos 70 - oferecem-nos pistas importantes sobre a forma como se configurou uma certa semântica sobre

${ }^{21}$ Diário da Assembleia da República, Sup. 17 (3.8.76), p. 438(65), apud VAKIL (2006, p. 81). 
o colonial-nacional que, ainda que com algumas variações, estão bem presentes na actualidade (ver também CARDOSO, 1998). Hoje, a "expansão" liga-se à singularidade de um contexto contemporâneo visto como crescentemente multicultural, no qual a suposta especificidade histórica do país o investiria de algumas vantagens, como na dita interculturalidade. ${ }^{22}$

Temos cada vez mais sociedades multiculturais, o que implica cada vez mais políticas interculturais [...] e que cada vez mais esta ideia de que aprendemos com os outros, e que a riqueza da diversidade só vem enriquecer as culturas e só vem enriquecer os países é algo central naquilo que Portugal, como um país com 4.5 milhões de nacionais espalhados pelo mundo, como um país que teve uma emigração fortíssima no último século, como um país sempre virado para este, para oeste, com toda a experiência que tivemos nos séculos XIV, XV, XVI e XVII e das saídas... e do contacto com outras culturas... Tudo isso, julgo que nos traz também uma responsabilidade grande a ter uma visão positiva sobre a diversidade (DECISOR POLÍTICO NA ÁREA DA INTERCULTURALIDADE).

Eu acho que vale a pena sempre insistir no aspecto de que os portugueses foram relativamente bem-sucedidos nessa questão multicultural, sobretudo através da mestiçagem e tudo isso... Acho que é qualquer coisa que vale a pena insistir - não sei bem como abordá-la - mas que vale a pena insistir porque isso não aconteceu com outras potências coloniais europeias... (HISTORIADOR 02).

Curiosamente, é na ideia de interculturalidade - de contacto, de trocas mútuas - que se privilegia uma das perspectivas, promovendo-se a tão ansiada imagem "positiva" de Portugal através da Expansão. O imaginário dos "dois lados" e as "consequências positivas e negativas" adquirem o estatuto de doutrina do consenso, apaziguadora de possíveis conflitos tidos como vãos. O seu labor de despolitização do colonialismo e da escravatura e a sua natureza reativa assentam na eficiente reprodução do mito da unidade (étnico-racial) de

${ }^{22}$ Neste processo de "democratização" das narrativas sobre as descobertas e a expansão, teve um lugar central a Comissão Nacional para as Comemorações dos Descobrimentos Portugueses (1986-2002) na projeção de um retrato renovado da identidade nacional e da sua história colonial: a interpretação das "Descobertas" como "diálogo intercultural" e dos portugueses como "mediadores culturais", substituindo assim a versão do Estado Novo de "mediadores raciais" (VAKIL, 1996, p. 36). 
Portugal, que relega a discussão sobre o racismo a um problema do (trazido pelo) "outro" e a tão proclamada mestiçagem e miscigenação "são discursivamente construídas como a passagem de sangue portuguesa para outros, mas raramente ao contrário" (VALE DE ALMEIDA, 2006, p. 22):

Nas vésperas do século XX, Portugal, um antigo Estado-nação com fronteiras políticas fixas desde o fim da Idade Média, era o Estado "ideal" imaginado pelos nacionalistas liberais. Estado e nação coincidiam em condições de homogeneidade cultural. Não havia minorias nacionais ou etnoculturais em Portugal, ou populações portuguesas em países vizinhos; de forma semelhante, Portugal não tinha minorias religiosas ou etnolinguísticas. Os dialetos eram raros, encontrados apenas em algumas zonas perto da fronteira espanhola. (PINTO, 1998, p. 1, tradução nossa). ${ }^{23}$

\section{REFERÊNCIAS}

ALTO-COMISSARIADO PARA IMIGRAÇÃO E MINORIAS ÉTNICAS - ACIME. Imigração: os mitos e os factos. Lisboa: ACIME, 2005.

. I Congresso Imigração em Portugal, 18 e 19 Dezembro 2003, Diversidade Cidadania - Integração. Lisboa: ACIME, 2004.

APPLE, M. The absent presence of race in education reform. Race, Ethnicity and Education, London, v. 2, n. 1, p. 9-16, jan. 1999.

ARAÚJO, M.; MAESO, S. R. O Eurocentrismo nos manuais escolares de História Portugueses. Estudos de Sociologia, São Paulo, v. 15, n. 28, p. 239-270, jan. 2010.

BALIBAR, É. (1988). Racisme et nationalisme. In: ; WALLERSTEIN, I. Race, nation, classe: las identités ambigués. Paris: La Découverte, 2007. p. 54-92.

BIBBY, H. C. Race, prejudice and education. London: Heinemann/Paris: UNESCO, 1959.

${ }^{23}$ Original: "On the eve of the twentieth century, Portugal, an old nation-state with political frontiers unchanged since the late Middle Ages, was the "ideal" state envisioned by Liberal nationalists. State and nation coincided in conditions of cultural homogeneity. There were no national or ethnocultural minorities in Portugal, or Portuguese populations in neighboring countries; similarly, Portugal had no religious or ethnolinguistic minorities. Dialects were rare, found only in some areas near the Spanish border." 
BROWN, W. Regulating aversion: tolerance in the age of identity and empire. Princeton, NJ: Princeton University Press, 2006.

CARDOSO, C. The colonialist view of the African-origin "other" in Portuguese society and its education system. Race, Ethnicity and Education, London, v. 1, n. 2, p. 191-206, jul. 1998.

CÉSAIRE, A. (1955). Discourse on Colonialism. New York: Monthly Review Press, 2000 .

COOPER, A. J. (1925). Slavery and the French and Haitian revolutions. Lanham-Maryland: Rowman \& Littlefield Publishers, 2006.

COSTA, J. P. O.; LACERDA, T. A interculturalidade na expansão portuguesa (Séculos $X V$-XVIII). Lisboa: ACIME, 2007.

COUNCIL OF EUROPE (CoE). Against bias and prejudice. The Council of Europe's work on history teaching and history textbooks (Recommendations on history teaching and history textbooks adopted at Council of Europe Conferences and Symposia 19531995). Strasbourg: Council for Cultural Co-operation, 1995.

. Mutual understanding and the teaching of European history: challenges, problems and approaches. Report of the Symposium held in Prague, 24-28 October 1995. Strasbourg: Council for Cultural Co-operation, 1996.

CRUZ, B. Don Juan and rebels under Palm Trees: depictions of Latin Americans in US history textbooks. Critique of Anthropology, v. 22, n. 3, p. 323-342, set. 2002.

CULPIN, C.; DAWSON, I.; BANHAM, D.; EDWARDS, B.; BURNHAM, S. SHP History Year 8. London: Hodder Education, 2009.

DU BOIS, W. E. B. The suppression of the African slave-trade to the United States of America 1638-1870. The Pennsylvania State University, Old Main, 2007. (A Penn State Electronic Classics Series Publication). Disponível em: <http://www2.hn.psu.edu/ faculty/jmanis/webdubois/DuBoisSuppressionSlavetrade.pdf $>$. Acesso em: 22/01/2012.

DUSSEL, E. Eurocentrism and modernity (Introduction to the Frankfurt Lectures). Boundary 1, Durham, North Carolina, v. 20, n. 3, p. 65-76, set. 1993.

. Europe, modernity, and “Eurocentrism”. Nepantla: Views from South, Durham, North Carolina, v. 1, n. 3, p. 465-478, set. 2000.

FANON, F. Peau noire, masques blancs. Paris: Seuil, 1952.

FREDRICKSON, G. M. Racism: a short story. Princeton: Princeton University Press, 2002.

FÜREDI, F. Mythical past, elusive future: History and society in an anxious age. London: Pluto Press, 1992 (reimpresso em 1993).

. The silent war: imperialism and the changing perception of race. New Jersey: Rutgers University Press, 1998. 
GOLDBERG, D. T. Modernity, race, and morality. Cultural Critique, Minneapolis, v. 24, p. 193-227, 1993.

The racial state. Oxford: Blackwell, 2002.

. The threat of race: reflections on racial neoliberalism. Malden, MA: Wiley-Blackwell, 2009.

HESSE, B. Forgotten like a bad dream: Atlantic slavery and the ethics of postcolonial memory. In: GOLDBERG, D. T.; QUAYSON, A. Relocating postcolonialism. Cornwall: Blackwell Publishing Company, 2002, p. 143-173.

. Im/plausible deniability: racism's conceptual double bind. Social Identities, London, v. 10, n. 1, p. 9-29, jan. 2004.

HICKLING-HUDSON, A. Cultural complexity, postcolonialism and educational change: challenges for comparative educators. International Review of Education, Hamburgo, v. 52, n. 1-2, p. 201-218, jan. 2006.

HIRA, S. Decolonizing the mind: the case of the Netherlands. Human Architecture: Journal of the Sociology of Self-knowledge, Belmont, MA, v. X, n. 1, p. 53-68, jan. 2012.

LENTIN, A. Europe and the silence about race. European Journal of Social Theory, London, v. 11, n. 4, p. 487-503, nov. 2008.

LESKO, N.; BLOOM, L. Close encounters: truth, experience and interpretation in multicultural teacher education. Journal of Curriculum Studies, London, v. 30, n. 4, p. 375-395, jun. 1998.

MAESO, S. R.; ARAÚJO, M. Portuguese (post-)colonial situations, national identity and the understanding of racism: the politics of academic narratives. Working Paper - Tolerace project, Coimbra, 2010. Disponível em: <http:/www.ces.uc.pt/projectos/ tolerace/pages/en/publications/working-papers/july-2010.php>. Acesso em: 19/01/2012.

MENESES, M. P. O “indígena” africano e o colono "europeu”: a construção da diferença por processos legais, E-cadernos CES, Coimbra, n. 7, p. 68-93, mar. 2010.

NIMAKO, K.; SMALL, S. Collective Memory of Slavery in Great Britain and the Netherlands. American Sociological Association Annual Meeting, Atlanta, 2010. Disponível em: $<$ http://africam.berkeley.edu/events/NIMAKO-SMALL.pdf $\geq$. Acesso em: 20/01/2012.

; WILLEMSEN, G. The Dutch Atlantic: slavery, abolition and emancipation. London: Pluto, 2011.

PINTO, A. C. Preface. In: PINTO, A. C. Modern Portugal. Palo Alto, California: The Society for the Promotion of Science and Scholarship, 1998. p. v-ix.

QUIJANO, A. Coloniality of power, eurocentrism and Latin America. Nepantla: Views from South, Durham - North Carolina, v. 1, n. 3, p. 533-539, set. 2000. 
. Coloniality and modernity/rationality. Cultural Studies, London, v. 21, n. 2, p. 168-178, mar. 2007.

SANTOS, B. de S. Beyond Abyssal thinking: from global lines to ecologies of knowledges. Review, Binghamton, NY, v. XXX, n. 1, p. 45-89, jan. 2007.

SAYYID, S. Slippery People: the immigrant imaginary and the grammar of colors. In: LAW, I.; PHILIPS, D.; TURNEY, L. Institutional racism in higher education. Stoke-on-Trent: TrethamBooks, 2004, p. 149-159.

STRADLING, R. Teaching 20th-century European history. Strasbourg: Council of Europe, 2001.

(Ed.). Crossroads of European histories: multiple outlooks on five key moments in the History of Europe. Strasbourg: Council of Europe, 2006.

SWARTZ, E. Emancipatory narratives: rewriting the master script in the School Curriculum. Journal of Negro Education, Washington DC, v. 61, n. 3, p. 341-355, out. 1992.

SWEET, J. H. Spanish and Portuguese influences on racial slavery in British North America, 1492-1619. V Annual Gilder Lehrman Center International Conference: Collective Degradation: Slavery and the Construction of Race, Yale University, New Haven 2003. Disponível em: < http://www.yale.edu/glc/events/race/Sweet.pdf $\geq$. Acesso em: 15/01/2012.

TINHORÃO, J. R. Os negros em Portugal: uma presença silenciosa. Lisboa: Caminho, 1988.

TROUILLOT, M. R. Silencing the past: power and the production of History. Boston: Beacon Press, 1995.

UNESCO. Handbook for the Improvement of Textbooks and Teaching Materials as Aids to International Understanding. Paris: UNESCO, 1949.

. Statement on the nature of race and race differences. Paris: UNESCO, 1951.

. The race concept: results of an inquiry. Paris: UNESCO, 1952.

. Recommendations made at the meetings held in Paris (1956), Tokyo (1958)

and Wellington (1960) on textbook improvement with reference to the East-West Major Project. Arquivos da UNESCO [WS/0562-12], Paris, 1962. Disponíveis em: <http:// unesdoc.unesco.org/images/0018/001848/184866eb.pdf $\geq$. Acesso em: 22/01/2012.

. International understanding at schools. Paris: UNESCO, 1967.

. Four statements on the race question. Paris: UNESCO, 1969.

. International Institute for Educational Planning, "Planning for Diversity: education in multi-ethnic and multicultural societies", Policy Forum n. 17, Paris, 2004. Disponível em: <http://unesdoc.unesco.org/images/0013/001390/139016e.pdf $\geq$. Acesso em: 10/01/2012. 
VAKIL, A. Nationalising cultural politics: representations of the Portuguese "Discoveries" and the rhetoric of identitarianism, 1880-1926. In: MAR-MOLINERO, C.; SMITH, A. Nationalism and the nation in the Iberian Peninsula. Oxford: Berg, 1996. p. 33-52.

. Heróis do lar, nação ambivalente: portugalidade e identidade nacional nos tempos dos pós. In: LOFF, M. 30 anos de democracia em Portugal. Porto: FLUP, 2006. p. 73-101. VALA, J.; BRITO, R.; LOPES, D. Expressões dos racismos em Portugal: perspectivas psicossociológicas. Lisboa: Instituto de Ciências Sociais, 1999.

VALE DE ALMEIDA, M. On the Lusophone postcolony: 'culture', 'race', 'language'. Department of Spanish and Portuguese Studies, Rutgers University, Newark, 2006. Disponível em: $<$ http://site.miguelvaledealmeida.net/wp-content/uploads/on-the-lusophone-postcolony1.pdf $\geq$. Acesso em: 22/01/2012.

VAN DIJK, T. Principles of critical discourse analysis. Discourse \& Society, London, v. 4, n. 2, p. 249-283, abr. 1993.

VERGÈS, F. 'There Are No Blacks in France': Fanonian discourse, 'The Dark Night of Slavery' and the French civilizing mission reconsidered. Theory, Culture \& Society, London, v. 27, n. 7- 8, p. 91-111, dez. 2010.

VITORINO, A. Imigração: oportunidade ou ameaça? Recomendações do Fórum Gulbenkian Imigração. Estoril: Principia, 2007.

WALLERSTEIN, I. Eurocentrism and its avatars: the dilemmas of social science. New Left Review, London, v. 1, n. 226, p. 93-107, nov.-dez. 1997.

\section{Manuais citados}

$\begin{array}{llll} & \text { Ano } & \text { Título e volume } & \text { Editora } \\ \text { LH8-1 } & 2009 & \text { História Oito }- \text { v. } 1 & \text { Lisboa Editora } \\ \text { LH9-1 } & 2009 & \text { História Nove }- \text { v. } 1 & \text { Lisboa Editora } \\ \text { VH8 } & 2008 & \text { Viva a História! } & \text { Porto Editora } \\ \text { H8-1 } & 2008 & \text { História } 8-\text { v. } 1 & \text { Texto Editores }\end{array}$

Texto recebido em 26 de maio de 2012.

Texto aprovado em 18 de julho de 2012. 